Rojas MiÑo, Irene. Subcontratación laboral, suministro de trabajo y cesión ilegal de trabajadores. Santiago, Chile: Editorial AbeledoPerrot/Thomson Reuters, 2011, XI + 196 pp.

Fruto de su proyecto de investigación "La externalización de las actividades laborales en las empresas: subcontratación y suministro de trabajo. Sus efectos jurídicos en las relaciones de trabajo", la abogada, doctora en derecho y académica de la Universidad de Talca, Irene Rojas Miño, publicó bajo el sello editorial LegalPublishing/Abeledo Perrot, un texto que aborda tres institutos jurídicos-laborales asociados al proceso de descentralización productiva: la subcontratación, el suministro de trabajadores y la cesión ilegal de trabajadores.

El libro se compone de una introducción (pp. 1-11); cinco capítulos que desarrollan "El fenómeno de la descentralización productiva y sus efectos en el Derecho del Trabajo y en los derechos de los trabajadores" (pp. 13-41), "Los cambios incorporados por el nuevo régimen jurídico de la subcontratación laboral” (pp. 43-90), "El suministro de trabajo" (pp. 91-121), "La cesión ilegal de trabajadores en el sistema jurídico chileno" (pp. 123-154) y "Desafíos del sistema jurídico frente a la subcontratación laboral, el suministro de trabajo y la cesión ilegal de trabajadores” (pp. 155-187), respectivamente; y un apartado de bibliografía (pp. 189-196).

En el primer capítulo de su obra, Rojas Miño explica el propósito de su investigación:

"El punto de partida en este estudio fue el de los desafíos que la realidad de las relaciones laborales plantea al Derecho del Trabajo y a partir de esa información se efectuó el análisis jurídico de la regulación de las instituciones jurídico-laborales objeto de este estudio, es decir, de la subcontratación laboral, del suministro de trabajo y de la cesión ilegal de trabajadores. Por consiguiente, hay dos objetos de análisis: el de los desafíos que plantean las manifestaciones indicadas de descentralización productiva y el de las mismas manifestaciones en su perspectiva de instituciones jurídicas laborales" (p. 5).

En otras palabras, la autora emprende un estudio que no se reduce a la mera exposición sistemática de la ley, sino que más bien pone de manifiesto las deficiencias legislativas, orientaciones de jurisprudencia y la opinio iuris sobre los temas objeto del libro y, cuestión no vista hasta entonces en los textos ${ }^{1}$, sugiere, en perspectiva crítica, las orientaciones que debiera guiar la legislación sobre la materia.

Informaremos sobre algunos tópicos del tomo para incitar a su lectura.

\title{
PLAN DE LA OBRA
}

Tal como indicábamos al comienzo, la obra no se reduce a una mera exégesis de la ley $\mathrm{N}^{\circ}$ 20.123 y demás disposiciones pertinentes. Al contrario, selecciona su exposición, centrándose en los aspectos legales, doctrinarios y jurisprudenciales más relevantes sobre la subcontratación, el suministro de trabajadores y la cesión ilegal de trabajadores.

\footnotetext{
Decimos "cuestión no vista", pues dedica un capítulo completo a "Desafíos del sistema jurídico frente a la subcontratación laboral, el suministro de trabajo y la cesión ilegal de trabajadores” (pp. 155-187), en comparación a los ya clásicos títulos de Palavecino CÁceres, Claudio. Subcontratación, Régimen jurídico del trabajo subcontratado y suministro de personal. Santiago de Chile: Editorial Jurídica de Chile, 2006 y Lizama Portal, Luis; Ugarte Cataldo, José Luis. Subcontratación y suministro de trabajadores. Santiago Chile: Editorial LexisNexis, 2007.
} 
Recensiones y Notas Bibliográficas

Esto coloca a la obra en un pie de superioridad metodológica, invitando al lector a un trabajo reflexivo sobre los tópicos tratados, con el afán de confrontar el contenido del texto con sus propias valoraciones.

\section{Visión agónica del Derecho del Trabajo}

Frente a la descentralización productiva la doctora Rojas describe los desafíos que plantea dicho fenómeno a las normas de derecho del trabajo, ya que a su juicio “...como consecuencia de la nueva organización de las empresas se está produciendo 'una desorganización del Derecho del Trabajo'; tanto sobre sus estructuras básicas del Derecho del Trabajo, como sobre los objetivos mismos de esta disciplina..." (p. 16).

Lo anterior es nuevo de puro añejo. Los laboralistas nacionales se cuestionan atónitos la eficacia de las normas laborales frente a la economía globalizada. Se habla de crisis del contrato de trabajo ${ }^{2}$, así como del fin de la historia, del fin del trabajo ${ }^{3}$. Quizás, sea la hora de preguntarse sobre la renovación de la disciplina frente a esta nueva organización del mundo, sumida, ahora, bajo el paraguas de la postmodernidad. Ello sin olvidar el velo proteccionista, consustancial e inherente a toda norma laboral el cual, junto a otros elementos, constituye el sustrato histórico del Derecho del Trabajo ${ }^{4}$ y que, con mayor o menor intensidad, se conserva en la generalidad de las legislaciones laborales actuales. Chile tomó ese camino cuando decidió conjugar la protección con las tres libertades cardinales en material laboral: de empresa, de trabajo y sindical.

\section{LA JURISPRUDENCIA COMO FUENTE DE DERECHO DEL TRABAJO}

La disciplina laboral bebe y se desarrolla, especialmente, en torno a la jurisprudencia -judicial y administrativa-, que junto a la doctrina y la ley han dado vida a excelentes obras jurídicas. La profesora Rojas comprende acabadamente su significación y utilidad, pues:

“...hay un dato de la realidad que nace directamente de una institución jurídica y esta es la de las sentencias judiciales, en la parte referida a los supuestos de hecho. Esta información constituye un material importante en el conocimiento de las formas que operan en la realidad las manifestaciones de la descentralización productiva, motivo por el cual, en diversas partes de este estudio, se efectúa un especial énfasis en su análisis..." (p. 7).

De ahí que el uso de una frondosa jurisprudencia sea una constante a lo largo del texto, a partir de una cuidadosa y detallada búsqueda que la autora se encarga de informar ${ }^{5}$. El material es utilizado de forma inteligente y no como un mero acople de información, de modo tal que muestra el desarrollo de las instituciones objeto de análisis imbricado con la realidad jurídica misma y, en consecuencia, con sus vaivenes y complejidades.

\footnotetext{
Galiana Moreno, Jesús M. "Crisis del contrato de trabajo", en: Revista de Derecho Socialno 2, España, 1998, pp. 47-65.

Rifkin, J. El fin del trabajo. Nuevas tecnologías contra puestos de trabajo. El nacimiento de una nueva era. España, Barcelona: Editorial Paidós, 1997, passim.

4 Para Adrián GOLDIN los elementos que configuran un Derecho del Trabajo básico histórico son: 1) El contrato de trabajo como expresión de libertad, pero a su vez de sometimiento (dependencia); 2) Esfuerzos por poner límites al sometimiento; 3) Mejora de esos límites; 4) Un nivel óptimo de libertad compartida (vgr. flexibilidad); 5) Desigualdad como presupuesto fáctico y como contrapartida de igualdad de dignidades; 6) Construcción de equilibrios en este escenario. Goldin, Adrián. Conferencia dictada en el marco de apertura del Congreso Mundial de Derecho del Trabajo. Santiago, Chile, septiembre 2012.

$5 \quad$ Notas al pie 7 y 8.
} 


\section{Sobre los EFECTOS DE LA LEY LABORAL EN EL TIEMPO}

A la luz de las situaciones de irretroactividad/retroactividad de la ley laboral, y a propósito de la aplicación de la ley No 20.123 a situaciones jurídicas ya constituidas a la época de dictación de la norma, la profesora Rojas plantea que los preceptos laborales, al ser de orden público rigen in actum (pp. 82, 83). Esta afirmación merece, al menos, ciertos matices.

Nadie cuestiona que las normas de derecho del trabajo sean de orden público, pero ello no significa que sean de derecho público y, en consecuencia, regulen todas y cada una de las situaciones jurídicas, pasadas, presentes y futuras. Al contrario, el manto de derecho privado que cubre a las normas del trabajo invita a cuestionar dicha aseveración.

\section{CONFIGURACIÓN DEL ILÍCITO DEL ARTíCULO 507}

Sobre los elementos que configuran el tipo del artículo 507 del CT (simulación) -ex artículo 478- la académica se pliega a la posición que sostiene la Dirección del Trabajo y parte de la doctrina, afirmando que la simulación de contratación de trabajadores a través de terceros constituye una infracción de fraude a la ley, prescindiendo de intención alguna. Se aleja, entonces, del concepto de simulación pues "el contenido que un sector le ha otorgado a la exigencia de simulación en la configuración de la infracción, obedece a un concepto doctrinal y no normativo, referido al ámbito del Derecho civil 'que en ningún caso vincula al intérprete laboral”' (p. 140).

Diferimos de dicha afirmación. Sin entrar en detalles sobre la minucia conceptual entre fraude a la ley y simulación, creemos que no existen los términos propios del derecho del trabajo para referirse, de una manera distinta, a conceptos que tienen su raíz en el derecho común. De lo contrario, sería algo distinto y no se podría utilizar el aparato conceptual propio del derecho civil. En el caso de la simulación sostenemos que, al menos, debe existir dolo indirecto ${ }^{6}$.

En síntesis, una obra que merece ser leída y estudiada por aquellos que cultivan el derecho del trabajo, tanto en su dimensión práctica como teórica.

Roberto Cerón Reyes

Palavecino Cáceres, Claudio. "El tipo subjetivo en la simulación y subterfugio en perjuicio de los trabajadores", en: http:// www.elmercurio.com/Legal/Noticias/Redes/Detallenoticia.aspx?id=901928 (sitio web visitado el 12 de mayo de 2013). 